\title{
Cognitive function in patients with Parkinson's disease undergoing stereotaxic thalamotomy
}

\author{
Morten Lund-Johansen, Kenneth Hugdahl, Knut Wester
}

\begin{abstract}
Objective-To determine whether thalamotomy leads to cognitive disturbances in patients with Parkinson's disease.

Methods-A total of 53 patients with Parkinson's disease undergoing stereotaxic ventrolateral thalamotomy for tremor and rigidity were tested for cognitive functions before and after surgery. The cognitive functions investigated involved visuospatial perception and memory, verbal memory, attention shift, and executive functions including set maintenance and shift. A neuropsychological test battery was used that contained the Wisconsin card sorting test, Street completion test, Stroop test, a dichotic memory listening test, and a facial recognition test.

Results-Clinically, a good or moderately good effect on parkinsonian symptoms was obtained in 50 patients. The neuropsychological investigation showed that the patients were impaired compared with healthy age matched control subjects on most tests, showing slight improvement postoperatively on verbal memory and visuospatial perception. No major differences were found between tests before and after operation, and there were no significant differences between patients undergoing surgery in the right or in the left thalamus.

Conclusion-The study indicates that ventrolateral thalamotomy does not reduce the cognitive capacity in this group of patients.
\end{abstract}

Department of Neurosurgery, University of Bergen Medical School, Haukeland Hospital, N-5021 Bergen, Norway

$M$ Lund-Johansen

K Wester

Department of Biological and Medical Psychology,

University of Bergen,

Aarstadveien 21,

N-5009 Bergen,

Norway

K Hugdahl

Correspondence to:

Dr Morten Lund-Johansen,

Department of

Department of

Neurosurgery, Haukeland

University Hospital

Received 5 June 1995

and in final revised form

4 January 1996

Accepted 12 January 1996

\section{(尹 Neurol Neurosurg Psychiatry 1996;60:564-571)}

Keywords: cognition; neuropsychology; Parkinson's disease; stereotaxy; thalamotomy

Stereotaxic thalamotomy is an effective symptomatic treatment in Parkinson's disease or other movement disorders. ${ }^{1-5}$ In this operation, normal nervous tissue in the ventrolateral thalamus is destroyed. Although the volume of the lesion is small (about $50 \mathrm{~mm}^{3}$ ), ${ }^{2}$ the target area has a critical location centrally in the brain, and adverse clinical effects may therefore be caused by thalamotomy. However, the risk of such complications is low, and most patients function better after the operation. ${ }^{3-5}$

The strategically important location of the thalamus in the diencephalon reflects its involvement in various functions, such as sen- sation, language, attention, and memory. ${ }^{6}$ Therefore, any of these functions may be affected as a consequence of a thalamotomy. Unless specifically investigated, such negative effects may pass unrecognised, overshadowed by the functional improvement that many patients experience when their parkinsonian symptoms are reduced.

Earlier studies of cognitive dysfunction after thalamotomy mainly dealt with language, and several studies from the pre-CT and prelevodopa era showed adverse effects from the operation..$^{7-9}$ We have previously reported changes in language perception in patients with Parkinson's disease during and after thalamotomy. Using dichotic listening, we found an acute reduction in the number of perceived syllables after left sided thalamotomies, with partial normalisation at three month follow up. ${ }^{10}$ In his 1992 review of language dysfunction in relation to thalamotomy, Crosson stated that since his 1984 review on the role of the thalamus in language "no significant data have accumulated". ${ }^{11}$ It is therefore uncertain whether or not thalamotomy does lead to cognitive disturbances in patients with Parkinson's disease.

In the present study, we have, therefore, applied a battery of neuropsychological tests to a group of parkinsonian patients who underwent stereotaxic thalamotomy. The selected tests cover broad functions such as memory, perception, attention, set shift and maintenance, and executive functions as well as hemispheric lateralisation. Furthermore, we have compared the preoperative data of the parkinsonian patients with those of age matched healthy subjects. Finally, as lesions in the speech dominant hemisphere might be considered more hazardous in terms of producing unwanted side effects, patients with surgery on the left and the right thalamus were analysed separately.

\section{Materials and methods}

PATIENTS

To be included in the study, the patients had to meet the following criteria:

(1) Clinical indication for thalamotomy with incapacitating drug resistant tremor, rigidity, or both and a history of Parkinson's disease lasting for more than two years.

(2) All patients were previously examined, diagnosed, and medically treated as having Parkinson's disease, and referred to our department from a practising neurologist or a neurological department. 
(3) Provided the patient consented to participate, he or she was presented with a neuropsychological test battery consisting of five different tests which were given preoperatively as well as postoperatively. Not all the patients were tested with all the tests (see later). For the patient to be included, at least one test had to be completed at both sessions (before and after operation).

Altogether 53 consecutive patients ( 42 men, 11 women, age range $43-74$, median 63 years) were included in the study. The clinical severity of Parkinson's disease in each patient was assessed with the Hoehn and Yahr scale, ${ }^{12}$ which ranges from 0 (no signs of disease) to 5 (confined to a wheelchair or bedridden unless aided). Twenty two patients were stage 1, 21 were stage 2 , seven were stage 3 , two were stage 4 , and one was stage 5 . The indication for thalamotomy was drug resistant severe tremor alone (32), rigidity alone (13), or both (eight). The thalamotomy was right sided in 28 and left sided in 25 patients. All patients were regularly taking levodopa. Three of the patients had previously undergone a thalamotomy with only temporary relief and the operation was repeated. These were tested for cognitive functions in connection with the ipsilateral reoperation. No patients were operated on bilaterally.

All patients were routinely admitted to the hospital three months after surgery for follow up including neuropsychological testing. The clinical evaluation of the effect of surgery was based on the patient's functional level before and after operation and scored into one of four categories: good if the tremor or rigidity had disappeared completely or nearly without any adverse side effects; moderate if the symptoms were reduced but still evident, or if the symptoms were abolished, but slight undesirable side effects reduced the gain of the operation; unchanged if no major effects could be seen; or worse if the patient's situation was impaired as a consequence of the operation. The parkinsonian symptoms are rarely increased as a result of a thalamotomy. Therefore, the category worse included patients in whom any adverse effects caused by the operation overshadowed the beneficial ones, leaving the patient in a worse situation. The above classification was based on the patient's own opinion as well as the evaluation made by the physician responsible. There was no disagreement between the patients' and the physicians' evaluations.

Before testing, the patients were checked for handedness using a Norwegian translation of the questionnaire developed by Raczkowski et $a l .{ }^{13}$ This consists of 14 questions related to manual functions, and one question related to a pedal item (kicking a ball). To be classified as a right hander, the patient had to indicate at least 13 items as performed by the right limb. All patients were right handed.

\section{CONTROLS}

The 53 patients were compared with age matched healthy control subjects without Parkinson's disease or dementia as tested with the mini mental state questionnaire. (For the Wisconsin card sorting and Street completion tests, standardised norms were used for comparison. ${ }^{14}{ }^{15}$ ) Unless otherwise noted in the text, the pre-operative scores of the patients were used for comparison with the controls.

\section{SURGERY}

All patients were operated on with a standard procedure by one surgeon (KW). Details have previously been published. ${ }^{10}$ The stereotaxic apparatus was of the Leksell type (Elekta Instruments, Stockholm, Sweden). The target area for thalamotomy was defined by CT, and located in the ventrolateral thalamic nucleus 2 $\mathrm{mm}$ behind the midcommissural plane, $3 \mathrm{~mm}$ above the intercommissural line, and $14 \mathrm{~mm}$ lateral from the midsagittal plane. Two electrodes were introduced into the target in a plane parallel to the posterior branch of the internal capsule, via a burr hole placed just anterior to the coronal suture, $3 \mathrm{~cm}$ from the midline. The electrode interdistance was 6 $\mathrm{mm}$, and the uninsulated electrode tip measured $2 \mathrm{~mm}$.

The lesions were produced by thermocoagulation with a maximum temperature of between $62^{\circ} \mathrm{C}$ and $65^{\circ} \mathrm{C}$. If the parkinsonian symptoms were not satisfactorily relieved by this procedure, a new lesion was placed 1 or 2 $\mathrm{mm}$ vertically adjacent to the first, along the same electrode tracks. Hence, the vertical extension of the lesion was 2,3 , or $4 \mathrm{~mm}$.

Cerebral CT was performed within three months before surgery, in connection with the stereotaxic procedure one to two days postoperatively, and at the follow up.

\section{NEUROPSYCHOLOGICAL TESTS}

The patients were tested in three sessions; the day before surgery, the day after surgery, and at follow up. At each session, which lasted for about an hour, a battery of five different neuropsychological tests was given in the following order: dichotic verbal memory test, Street completion test, Bergen facial recognition test, Stroop test, and Wisconsin card sorting test; (table 1). Only data from the preoperative and follow up tests are presented here. A total of 28 patients completed all tests in both sessions. The remaining patients completed one test (eight), two tests (one), three tests (four), or four tests (12 patients).

A brief description of the tests is given below.

\section{Dichotic memory test}

The dichotic memory test has previously proved sensitive in reflecting changes in verbal memory in localised head traumas ${ }^{16}$ and intracranial expansive lesions. ${ }^{17}$

The dichotic stimuli consisted of six lists of 10 common Norwegian nouns and verbs which were presented with free intervals of two seconds via headphones to one ear of the subject, and with each word simultaneously presented in reverse to the opposite ear. After the first 10 word/inverse word pairs, the experimenter told the subject to repeat as many of the words as he or she could remember (immediate free recall), 
Table 1 Neuropsychological test battery applied to 53 Parkinson patients who underwent stereotactic thalamotomy: main functions investigated by the tests and a brief summary of the findings

\begin{tabular}{|c|c|c|c|}
\hline Test & Function investigated & $\begin{array}{l}\text { Parkinson Patients } v \\
\text { control subjects }\end{array}$ & $\begin{array}{l}\text { Preoperative v } \\
\text { postoperative }\end{array}$ \\
\hline Wisconsin card sorting test & $\begin{array}{l}\text { Executive function, attention } \\
\text { shift, set formation and } \\
\text { maintenance }\end{array}$ & $\begin{array}{l}\text { Lower number of categories, } \\
\text { within control range for } \\
\text { errors }\end{array}$ & No difference \\
\hline Stroop test & As above & $\begin{array}{l}\text { Slower than controls, more } \\
\text { errors }\end{array}$ & No difference \\
\hline Bergen facial recognition test & $\begin{array}{l}\text { Visuospatial function, spatial } \\
\text { perception and memory }\end{array}$ & $\begin{array}{l}\text { Recalled fewer items when } \\
\text { more than one face was } \\
\text { presented }\end{array}$ & No difference \\
\hline Street completion test & As above & Recognised fewer items & Postoperative improvement \\
\hline Dichotic verbal memory test & Verbal memory & Recalled fewer items & $\begin{array}{l}\text { Better recall from left ear } \\
\text { postoperatively }\end{array}$ \\
\hline
\end{tabular}

and scored the number of correct words. The next list of words was presented to the alternate ear after about 20 seconds, the starting ear being randomised. The test was continued until the subject had received and responded to all

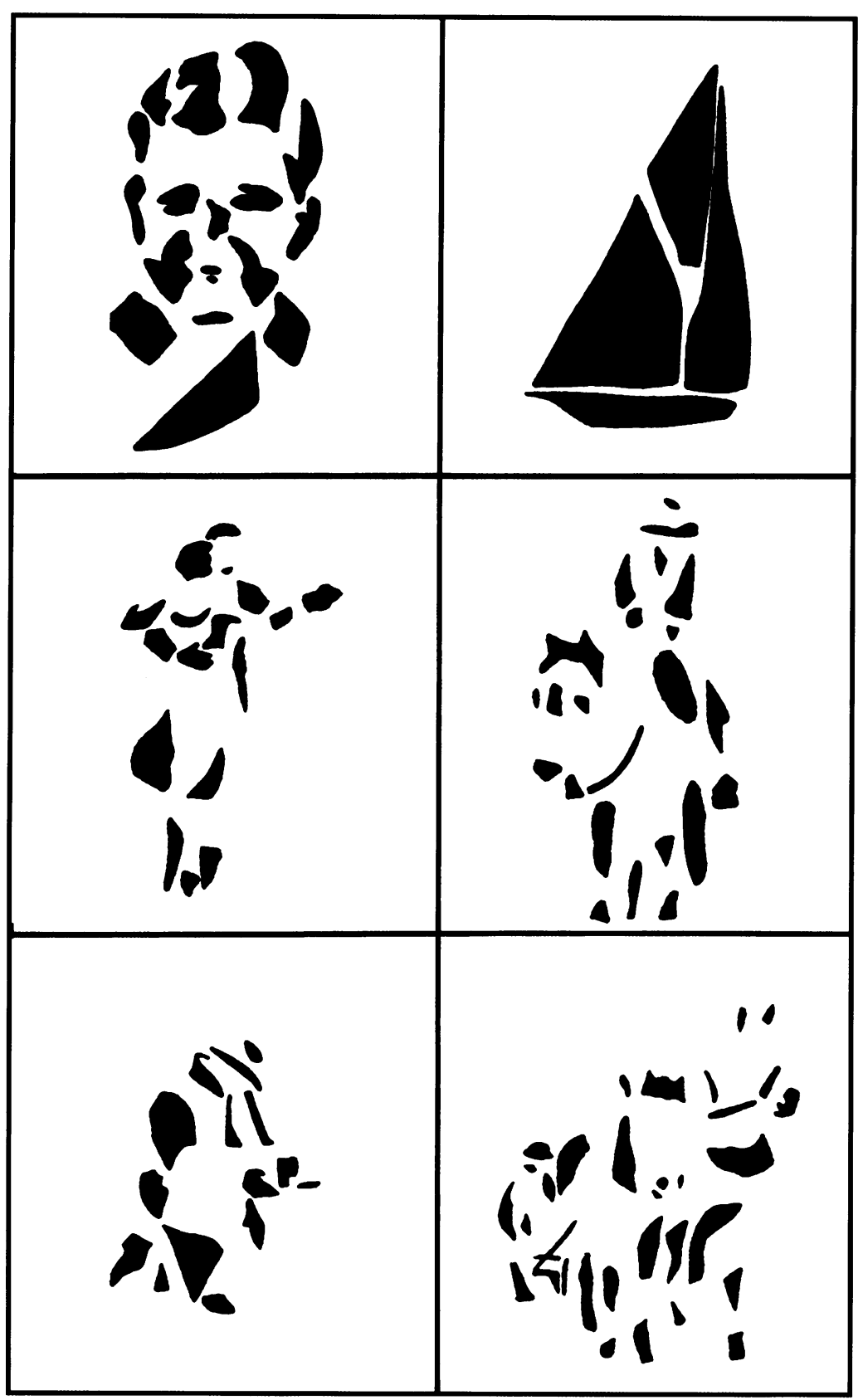

Figure 1 Examples of displays used in the Street completion test. The task of the patient is to identify the object on each stimulus card. There are 20 cards in the test, with increasing difficulty due to filtering of stimulus elements. six lists of words. In order not to present the subject with the same word lists on each test occasion, three different versions of the test were used. The words were read on to a chrome-dioxide cassette and played to the subject from a Sony WM DD-II minicassette player through SONY plug-in type earphones, the experimenter receiving the same information simultaneously from an additional headset.

Memory was scored for right and left ear separately, and the average of the two values was calculated as well.

\section{Street completion test}

This is a test based on the Gestalt psychology principle of "visual closure" and measures visual perception and recognition. It is particularly sensitive to right hemispheric dysfunction. ${ }^{18}$ The present version was the one used by Gade et $a l^{19}$ and consists of 20 black and white pictures that are progressively difficult to recognise because of degradation of stimulus information in the pictures (for example, see fig 1). The subject was shown each picture for 10 seconds and told to identify the displayed object. Each correct answer was scored.

\section{Bergen facial recognition test}

This test was designed by one of us $(\mathrm{KH})$, and was included to evaluate the existence of a visuospatial deficit in parkinsonian patients. ${ }^{20} \mathrm{It}$ also taps spatial memory. ${ }^{2122}$ The subject was presented with a series of nine line drawings showing a symmetric cartoon type face, in which the curving and angle of the eyebrows and mouth each varied in three different modalities, hence allowing a total of nine different variations of the drawing (fig 2). Each face was presented on a $21 \times 29 \mathrm{~cm}$ card for five seconds and then removed, and the subject was then asked to identify the correct face on a reference card showing all nine faces. After nine single faces had been shown, cards with two faces were shown, thus requiring the identification of two faces from the reference card. In the third run, cards with three faces were used, and after removal of the stimulus the subject was similarly told to identify the three correct faces on the reference card. Each correct answer was scored.

\section{Stroop test}

The Stroop test measures the ability to shift attentional set in order to conform to changing demands. ${ }^{1423}$ Furthermore, it measures the 

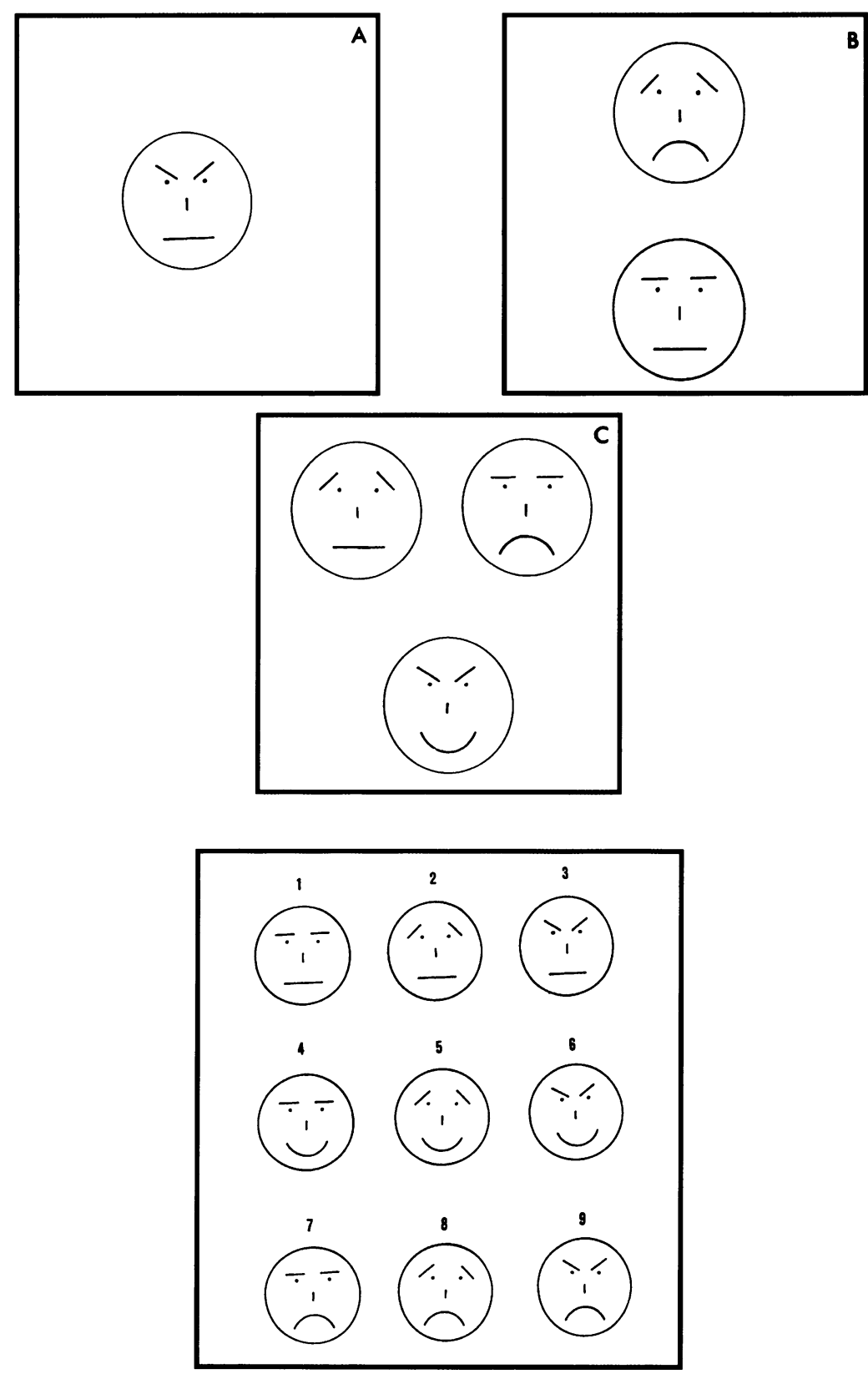

Figure 2 Outline of the Bergen facial recognition test (BFRT).(A) Example of the single face stimulus card (total of nine single cards). Each face displays an emotion ranging from positive through neutral to negative by varying the angle of the eyebrows $/ \backslash, 1 /$, or - - and the curve of the mouth, up, down, or straight line. (B) Two stimulus faces shown simultaneously to the patient. (C) Three faces presented simultaneously. At the bottom is the reference card. This is shown to the patient after each single, two, or three faces display, and the patient responds by naming the numbers that correspond to the faces shown on the stimulus card. words, all written in incongruent colours (such as the word "RED" written in blue). The subject was asked to name the colour of each word, ignoring the word information, as fast as possible. The cards were presented in order as described above, to maximise the Stroop effect due to verbal priming from the reading task in card 2 to the interference colour naming task in card 3.

\section{Wisconsin card sorting test}

This test deals with frontal lobe executive function, abstract concepts, and shift and maintenance of attentional and motor sets. ${ }^{14} 1524$ The test is often used in neuropsychology. For a detailed description see Heaton. ${ }^{15}$ Briefly, in the version used in this study the test person was presented with four stimulus cards laid next to each other on a table. Card 1 showed a red triangle, card 2 two green stars, card 3 three yellow crosses, and card 4 four blue dots. The patient was then asked to sort a deck of 64 cards similarly designed into four piles in response to the experimenter, who responded "right" or "wrong" each time the test subject placed a card into one of the four piles. The experimenter changed the sorting criteria (colour, shape, number) in a standardised fashion during the test without the test subject knowing. The subject being tested therefore had to find out and adapt to the new criterion each time it was changed. The number of sorting categories, errors, and perseverative errors were scored.

\section{STATISTICAL METHODS}

For the comparison of preoperative versus postoperative data in the same group of patients, a type 2 two tailed Student's $t$ test for dependent samples was used.

When the right versus left operated patients were compared, as well as when the patients were compared with the controls, a type 1 two tailed $t$ test for independent samples was used. In both circumstances, the limit of statistical significance was defined as $P<0.05$.

A separate analysis of variance (ANOVA) was performed on the verbal memory data, to evaluate interaction effects related to ear asymmetry due to the dichotic presentation mode.

ability to suppress the brain's "default" setting to first process semantic information in a stimulus compound, when there is additional competing information in the compound. In the version of the Stroop test used here, three $21 \times 29 \mathrm{~cm}$ cards were used. The stimuli on each card were arranged in a $6 \times 8$ matrix. The first card consisted of 48 colour dots (green, blue, yellow, red, white, and black), and the subject was asked to name the colour of each dot as fast as possible. Naming time, errors, and self corrected errors were scored (similarly in all three cards). The second card displayed 48 colour words (the same colours as in card 1) written in black against a white background. The subject was asked to read the words as fast as possible. The third card showed 48 colour

\section{Results}

\section{CLINICAL EFFECT AND CT FINDINGS}

At follow up, the clinical effect of the operation was scored as "good" in 43 patients. In seven patients there was a "moderate" beneficial effect, two were "unchanged," and one patient was regarded as "worse." This was a man aged 70 years who had a $3 \mathrm{~mm}$ high lesion in the right thalamus. This led to a complete relief of rigidity, but he developed a permanent reduction of muscle tone in his left side, probably caused by effects on the internal capsule. As a result he had a tendency to fall to the left, and his walking ability was impaired. $\mathrm{mm}$ in the right thalamus and $2.56 \mathrm{~mm}$ in the
The average height of the lesion was 2.96 
Table 2 Dichotic verbal memory test: data from 53 patients with Parkinson's disease and 32 age related normal control subjects

\begin{tabular}{llll}
\hline Side of lesion & $\begin{array}{l}\text { Test } \\
\text { occasion }\end{array}$ & $\begin{array}{l}\text { Left ear } \\
\%(S D)\end{array}$ & $\begin{array}{l}\text { Right ear } \\
\%(S D)\end{array}$ \\
\hline Right $\mathrm{n}(\mathrm{n}=28)$ & Preop & $22 \cdot 3(11 \cdot 1)^{\star}$ & $24 \cdot 8(10 \cdot 5)^{\star}$ \\
& Postop & $27 \cdot 3(14 \cdot 1)^{\star} \dagger$ & $29 \cdot 1(16 \cdot 0)^{\star}$ \\
Left $(\mathrm{n}=25)$ & Preop & $24 \cdot 7(15 \cdot 6)^{\star}$ & $30 \cdot 7(11 \cdot 7)^{\star}$ \\
& Postop & $28 \cdot 4(14 \cdot 7)^{\star} \dagger$ & $32 \cdot 2(13 \cdot 7)^{\star}$ \\
Controls $(\mathrm{n}=32)$ & & $44 \cdot 9(16 \cdot 0)$ & $39 \cdot 2(13 \cdot 9)^{\star}$
\end{tabular}

Data are \% correct responses (SD). ${ }^{\star}$ Significantly different from controls. +Significantly different from preoperative values.

Table 3 Street completion test: data from 46 patients with Parkinson's disease and 30 age related healthy control subjects

\begin{tabular}{lll}
\hline Side of lesion & Test occasion & $\begin{array}{l}\text { Correct recognition } \\
\%(S D)\end{array}$ \\
\hline Right $(\mathrm{n}=25)$ & Preop & $52 \cdot 9(20 \cdot 6)^{\star}$ \\
Left $(\mathrm{n}=21)$ & Postop & $60.9(21 \cdot 7)^{\dagger}$ \\
Controls $(\mathrm{n}=30)$ & Preop & $52 \cdot 5(18 \cdot 0)^{\star}$ \\
\hline
\end{tabular}

Data are \% correct responses (SD). ${ }^{\star}$ Significantly different from controls. +Significantly different from preoperative values.

left; this difference was statistically significant (type 1 two tailed $t$ test, $\mathrm{P}=0.05$ )

There was no difference in surgical outcome between patients operated on the left or the right side. The first postoperative CT typically showed a diffusely demarcated hypodense lesion with a diameter of $5-10 \mathrm{~mm}$ in the region of the ventrolateral nucleus of the thalamus on the operated side. Usually, a sharply demarcated and much smaller lesion remained detectable on the scans obtained at the three month control.

\section{NEUROPSYCHOLOGICAL TESTS}

There was no significant difference in the number of tests that each patient succeeded in performing before versus after operation (not shown). The reason why some patients did not complete all tests was usually fatigue. Furthermore, a few patients at the beginning of the study were not given all five tests. Three patients were excluded from the Stroop and the Wisconsin tests because of colour blindness. Table 1 presents the main findings of the test studies.

Table 4 Bergen facial recognition test: data from 42 patients with Parkinson's disease and 30 healthy age related control subjects

\begin{tabular}{lllll}
\hline Side of lesion & Test occasion & $\begin{array}{l}\text { One face } \\
\%(S D)\end{array}$ & $\begin{array}{l}\text { Two faces } \\
\%(S D)\end{array}$ & $\begin{array}{l}\text { Three faces } \\
\%(S D)\end{array}$ \\
\hline Right $(\mathrm{n}=21)$ & Preop & $64 \cdot 5(22 \cdot 9)$ & $44 \cdot 0(24 \cdot 3)^{\star}$ & $40 \cdot 2(32 \cdot 2)^{\star}$ \\
Left $(\mathrm{n}=21)$ & Postop & $65 \cdot 1(22 \cdot 0)$ & $44 \cdot 6(23 \cdot 0)^{\star}$ & $38 \cdot 6(25 \cdot 3)^{\star}$ \\
Controls $(\mathrm{n}=30)$ & Preop & $64 \cdot 5(24 \cdot 2)$ & $48 \cdot 2(24 \cdot 5)^{\star}$ & $33 \cdot 9(24 \cdot 4)^{\star}$ \\
& Postop & $69 \cdot 8(20 \cdot 6)$ & $41 \cdot 7(22 \cdot 9)^{\star}$ & $41 \cdot 8(18 \cdot 4)^{\star}$ \\
\hline
\end{tabular}

Data are \% of correct responses (SD). *Significantly different from control.

\section{Dichotic memory listening}

Compared with the controls, the patients recalled significantly fewer items from the 10word lists $(P<0.05$; table 2$)$.

For both lesion sides, there was an improved postoperative recall from the left ear $(P<0.05)$. A separate analysis of variance (ANOVA) was performed to evaluate any differences between the right and left ear scores for patients and controls. The ANOVAs were performed separately on the preoperative and postoperative data, and no significant ear advantage was found among the patients.

\section{Street completion test}

The patients performed significantly worse than the control subjects $(P<0.05)$. When tested at follow up, however, the performance level of the patients improved significantly ( $P<0.05$, both lesion sides) with no difference from the normative data (table 3 ).

\section{Bergen facial recognition test}

When the recognition of only one face was required, the patients responded within the range of the control subjects. However, when the demand was increased to two or three faces, the patients' performance dropped significantly below that of the controls $(\mathrm{P}<0.05)$.

The surgery did not significantly affect the performance of the patients (table 4).

\section{Stroop test}

The patients were significantly slower than the controls in responding to card 1 (colour dots) and card 3 (incongruent colour/word) of the test $(P<0.05)$. Furthermore, the patients produced more errors than the controls when reading card 3 (table 5 ).

Surgery did not significantly affect performance on any aspect of the Stroop test when values before and after operation were compared (both lesion sides). At follow up, the patients with surgery on the right thalamus produced fewer errors and self corrected errors when reading card 3, but this improvement failed to reach statistical significance.

\section{Wisconsin card sorting test}

When compared with the closest fitting age matching norms, presented by Spreen and Strauss $^{14}$ for subjects aged 60-79 years, the patients performed $2 \mathrm{SD}$ below the normal mean when comparing number of categories achieved (table 6). The Spreen and Strauss norms do not contain errors and perseverative errors. These variables were therefore compared with the norms of Heaton ${ }^{15}$ and were found to be within the normal range, differing

Table 5 Stroop test: data from 32 patients with Parkinson's disease and 30 healthy age related control subjects

\begin{tabular}{|c|c|c|c|c|c|c|c|c|c|c|}
\hline Side of lesion & Test occasion & Card 1 (SD) & Errors & $C$ errors & Card $2(S D)$ & Errors & $C$ errors & Card $3(S D)$ & Errors & $C$ errors \\
\hline Right $(n=14)$ & Preop & $40.4(12 \cdot 6)^{\star}$ & $0.9(1.2)$ & $0.7(1 \cdot 1)$ & $24 \cdot 2(11 \cdot 6)$ & $0.1(0.5)$ & 0 & $96.6(49.5)^{\star}$ & $4 \cdot 2(5 \cdot 2)^{\star}$ & $1.3(1.5)$ \\
\hline & Postop & $38.7(10.9)$ & $0.4(0.6)$ & $0.1(0.4)$ & $22.8(5.5)$ & $0.1(0.3)$ & 0 & $92.0(45 \cdot 1)^{\star}$ & $2 \cdot 4(3.0)$ & $0.9(1.3)$ \\
\hline Left $(n=18)$ & Preop & $40.9(13.0)^{\star}$ & $0.1(0.2)$ & $0.2(0.4)$ & $23.6(7 \cdot 8)$ & $0.2(0.5)$ & 0 & $85 \cdot 1(30.4)^{\star}$ & $7 \cdot 7(12 \cdot 6)^{\star}$ & $1.5(2.4)$ \\
\hline & Postop & $44.6(13 \cdot 6)^{\star}$ & $0.3(0.5)$ & $0.5(0.8)$ & $25 \cdot 5(9 \cdot 4)$ & $0.1(0.2)$ & 0 & $98.7(44.4)^{\star}$ & $4 \cdot 3(4 \cdot 6)^{\star}$ & $3 \cdot 1(3 \cdot 2)$ \\
\hline Controls $(n=30)$ & & $33 \cdot 1(7 \cdot 9)$ & $0.2(0.6)$ & $0.3(0.8)$ & $20 \cdot 1(3 \cdot 3)$ & 0 & $0.1(0.3)$ & $68 \cdot 8(21 \cdot 8)$ & $1 \cdot 2(2 \cdot 3)$ & $1 \cdot 2(1 \cdot 6)$ \\
\hline
\end{tabular}

Data are mean time required to read the three cards (SD), number of errors (SD), and number of self corrected errors (C errors) (SD).

¿ Significantly different from control.
. 
Table 6 Wisconsin card sorting test: data from 36 patients with Parkinson's disease compared with standardised norms ${ }^{14}$ is

\begin{tabular}{|c|c|c|c|c|}
\hline Side of lesion & Test occasion & $\begin{array}{l}\text { Number of } \\
\text { categories } \\
\%(S D)\end{array}$ & $\begin{array}{l}\text { Errors } \\
\%(S D)\end{array}$ & $\begin{array}{l}\text { Perseverative errors } \\
\%(S D)\end{array}$ \\
\hline Right $(\mathrm{n}=17)$ & Preop & $2.6(1.9)$ & $38 \cdot 7(19 \cdot 2)$ & $8.5(6 \cdot 8)$ \\
\hline Left $(n=19)$ & Postop & $2 \cdot 3(2 \cdot 0)$ & $41 \cdot 6(19 \cdot 5)$ & $11 \cdot 5(10 \cdot 2)$ \\
\hline Left $(n=19)$ & $\begin{array}{l}\text { Preop } \\
\text { Postop }\end{array}$ & $\begin{array}{l}2 \cdot 4(1 \cdot 6) \\
2 \cdot 2(1 \cdot 5)\end{array}$ & $\begin{array}{l}38.4(13.7) \\
35.9(17.4)\end{array}$ & $\begin{array}{r}9 \cdot 3(8 \cdot 26) \\
10 \cdot 5(12 \cdot 5)\end{array}$ \\
\hline Norms & & $5 \cdot 6(1 \cdot 1)$ & $32.5(15.8)$ & $11.8(8.9)$ \\
\hline
\end{tabular}

Errors and perseverative errors are \% of total responses (SD).

from the standardised norms by less than $0 \cdot 5$ SD.

For both lesion sides, the performance did not change significantly after surgery.

\section{INDIVIDUAL PATIENTS}

When the patients were analysed as a group, surgery did not seem to impair the patients neuropsychologically. However, the possibility might exist that individual patients were impaired. To investigate this, we compared all tests before and after operation for each of the 27 patients who had gone through all the five tests on both test occasions. There were no patients who showed impairment on all tests. Seven patients had lower scores on four tests postoperatively. In these cases, however, the differences between values before and after operation were usually small.

Furthermore, an increasing age may be associated with a progressive risk of developing postoperative cognitive impairment. Therefore, we investigated if there was any correlation between the patients' age and the cognitive outcome (postoperative versus preoperative neuropsychological state). No such relation with age was found for any of the tests (not shown).

\section{Discussion}

\section{CLINICAL EFFECT OF STEREOTAXIC}

THALAMOTOMY

The vast majority of patients in this study had a clinical benefit from their thalamotomy, and the results were similar to those reported by other groups..$^{3-5}$ Although there was a transient slight hemiparesis in some patients postoperatively, their overall outcome was nevertheless good at follow up, because the tremor and rigidity were reduced to a minimum. We could not follow up the patients for longer than three months. However, as reported, a few patients have been referred back to our department for reoperation, which was carried out six to 12 months after the first operation.

Clinically, the effect of surgery was similar in the right and the left hemisphere. However, the right sided lesions were slightly, but significantly larger than those made in the left thalamus. When performing a thalamotomy, the surgeon is faced with the dilemma of generating a lesion that is large enough to relieve the symptoms, yet small enough not to cause adverse side effects, such as hemiparesis or language difficulties. In most subjects, the language dominant hemisphere is found on the left side. We think that in left sided thalamotomies, considerable attention should be paid to the language aspect, and that the difference in lesion size may reflect the surgeon's consideration of this matter.

\section{Cognitive functions}

Two main conclusions can be drawn when reviewing the data from the neuropsychological tests. Firstly, the parkinsonian patients' preoperative cognitive functions were reduced in comparison with those of healthy subjects. Secondly, the operation apparently did not impair the patients' cognition, because the preoperative and postoperative results were similar. In some tests, the patients as a group showed postoperative improvement. This improvement, which was found in the verbal memory and the Street completion tests, is likely to be caused by learning effects of the repeated test situations. We do not think that the operation in fact improved the patients' cognition. The patient and control groups were not matched for premorbid IQ or dementia. This may be done in future studies.

The relative failure to show clear adverse effects of thalamotomy on cognition is somewhat at odds with previous reports. Vilkki found that patients with surgery on the left side were more affected than patients with surgery on the right side when tested for visual search, showing a type of hemispatial neglect. ${ }^{25}$ Almgren et al found that patients with left sided thalamotomy were more impaired than patients with a right sided thalamotomy on both a verbal memory test and the Stroop task. ${ }^{26}$ However, none of these authors found that cognitive function was in general impaired after the operation. The sample sizes were small in both studies, hence making it difficult to draw definitive conclusions. Another possible explanation of the discrepancies between our results and previous studies is that there has been a tendency to produce smaller and more refined lesions during recent years; for example, our lesions seem to be somewhat smaller than those of Vilkki. ${ }^{25}$ Thalamotomy lesions have been made in different thalamic target areas. ${ }^{27}$ Thus the location of the lesion within the thalamus may also be crucial in eliciting or avoiding cognitive deficts.

\section{Visuospatial function}

When testing visuospatial function, it is important to use tests in which the motor requirement is low or absent, to separate a possible visuospatial dysfunction from the motor impairment found in Parkinson's disease. The Street completion and the facial recognition tests fulfil these criteria as the patient's response is exclusively verbal. Previous studies suggest that patients with Parkinson's disease are impaired on visuospatial functions such as judgement of line orientation and face recognition. ${ }^{2028}$ Our results from the Street completion and facial recognition tests are in line with these earlier findings, thus supporting the hypothesis that a visuospatial dysfunction is actually a clinical feature of Parkinson's disease. ${ }^{29}$ Table 4 shows that in comparison with the control subjects, this dysfunction became most obvious when 
the memory load was increased. Similarly, the patients were particularly inferior to the controls on the last part of the Street completion test, in which the perceptual load on visuospatial ability is increased compared with the first part of the test. However, as no negative effect of the operation was found, we conclude that thalamotomy did not further impair visuospatial function.

\section{Dichotic memory}

The dichotic presentation of the word lists in the verbal memory test enabled us to study lateralised effects, and to relate eventual asymmetries in memory function to the side of the lesion. As the left hemisphere is usually language dominant, a lesion in the left thalamus might theoretically produce deficits that could be recognised as an impaired recall, particularly from the right ear. Our results, however, do not support this theory, because we did not find any interaction between the side of the lesion and an ear advantage. The improved recall from the left ear postoperatively was independent of side of lesion, and may be the result of a learning effect. (see Hugdahl and Wester $^{30}$ for a review of the use of dichotic listening in asymmetry studies of patients with brain damage.)

\section{Executive and set function}

For executive function and set maintenance/ shift as investigated by the Wisconsin card sorting and Stroop tests, the patients again showed deficits compared with the normative data. Bowen et al suggested that these deficits were specific to "switch cognitive set", rather than attributed to a visuospatial dysfunction. ${ }^{31}$ It was suggested that the impairment in Parkinson's disease was related to the patients' failure to shift their perspective repeatedly between two spatial orientations (as when shifting from the word to the colour in the Stroop task). Our patients were not inferior to the controls for errors and perseverative errors on the Wisconsin card sorting test, although they performed $2 \mathrm{SD}$ below the norms on some categories (table 6). This is in line with the report by Taylor et al, who concluded that "while the Parkinson patients generated significantly fewer categories, they did not characteristically indulge in a perseverative response style" ${ }^{32}$ Furthermore, Lichter et al did not find any increase in perseverative errors in Parkinson's disease. ${ }^{33}$ Taylor et al found that their parkinsonian patients required more trials to reach the first category (colour). ${ }^{32}$ Our findings are in agreement with this, because our patients required many trials to get the first category right. The category "colour" was particularly ignored, many patients tried "number" and "form" repeatedly during the first trials (not shown).

It is our impression that the largest "gap" in cognitive function between patients and controls was shown by the Stroop test. The results from this test support the suggestion by Brown and Marsden that patients with Parkinson's disease are impaired on cognitive tasks that require internal cuing for attentional shifts, but that they are relatively unimpaired when external cues are given. ${ }^{34}$ Because the Stroop test requires the subject to internally generate the "colour" cue on each stimulus display, the patients should be expected to perform worse than normal controls. This was appropriately shown in the present data, with an increase in the difference between the patients and controls when comparing performance on cards 1 and 2 , with card 3 (being the Stroop interference card). The easiest task is to read the words on card 2, and this did not differentiate between the patients and the controls. Thus although the patients performed below the normal controls also on the simple colour naming task, they were particularly impaired in the interference task on card 3.

\section{Conclusions}

Parkinsonian patients scored significantly below normal controls when tested with a battery of neuropsychological tests dealing with cognitive functions. Furthermore, our data suggest that cognitive impairment was not affected by thalamotomy. The impaired functions fall mainly into the categories of visuospatial and memory functions, and shifting and maintaining attentional set. Although the ventrolateral nucleus has connections to several cortical areas (for example, precentral and frontal gyri) that may affect cognitive processes when lesioned, the operation obviously does not disrupt the functional integrity of these cortical areas. The role of the nonspecific reticular nucleus in ventrolateral thalamotomy is speculative. The reticular nucleus borders the ventrolateral nucleus laterally, and has connections to the ventrolateral nucleus. An unproved hypothesis is that ventrolateral thalamotomy may interfere with arousal or activation mechanisms. ${ }^{35}$ This hypothesis may be tested in future studies by including tests of vigilance and activation.

1 Spiegel EA, Wycis HT. Stereo-encephalotomy (thalamotomy and related procedures). Part 1. New York: Grune and and related proced

2 Hirai T, Miyazaki M, Nakajima H, Shibazaki T, Ohye C. The correlation between tremor characteristics and the predicted volume of effective lesions in stereotaxic nucleus ventralis intermedius thalamotomy. Brain 1983; 106:1001-18.

3 Kelly, PJ. Stereotactic thalamotomies. In: Koller WC, Paulson G, eds. Therapy of Parkinson's disease. New York: Marcel Derker, 1990:415-42.

4 Matsumoto $\mathrm{K}$, Shichijo F, Fukami T. Long-term follow-up review of cases of Parkinson's disease after unilateral or bilateral thalamotomy. $\mathcal{f}$ Neurosurg 1984;60:1033-44.

5 Wester K, Hauglie-Hanssen E. Stereotaxic thalamotomyexperiences from the levodopa era. $\mathcal{F}$ Neurol Neurosurg Psychiatry 1990;53:427-30.

6 Crosson B. Subcortical functions in language and memory. New York: The Guilford Press, 1992.

7 Selby G. Stereotactic surgery for the relief of Parkinson's disease I. A critical review. F Neurol Sci 1967;5:315-42.

8 Selby G. Stereotactic surgery for the relief of Parkinson's disease II. Analysis of the results of a series of 303 disease II. Analysis of the results of a series of 303
patients (413 operations). $₹$ Neurol Sci 1967;5:343-75.

9 Samra K, Riklan M, Levita E, et al. Language and speech correlates of anatomically verified lesions in thalamic surgery for parkinsonism. If Speech Hear Res 1969;12: $510-40$.

10 Hugdahl $\mathrm{K}$, Wester $\mathrm{K}$, Asbjørnsen A. The role of the left and right thalamus in language asymmetry: dichotic listening in parkinson-patients undergoing stereotactic thalamotomy. Brain Lang 1990;39:1-13

11 Crosson B. Role of dominant thalamus in language: a review. Psychol Bull 1984;96:491-517.

12 Hoehn MM, Yahr MD. Parkinsonism, onset, progression and mortality. Neurology 1967;17:427-42. 
13 Raczkowski D, Kalat JW, Nebes RD. Reliability and validity of some handedness questionnaire items. Neuropsychologia 1974;12:43-7

14 Spreen O, Strauss E. A compendium of neuropsychological tests: administration, norms, commentary. New York: Oxford University Press, 1991.

15 Heaton R. Wisconsin card sorting test manual. Odessa, FL: Psychological Assessment Resources, Inc, 1981.

16 Christianson $S \AA$, Nilsson LG, Silfvenius H. Initial memory deficit and subsequent rcovery in two cases of head trauma. Scand $¥$ Psychol 1987;28:267-80.

17 Wester K, Hugdahl K. Arachnoid cysts of the left temporal fossa: impaired preoperative cognition and postoperative improvement. $\mathcal{F}$ Neurol Neurosurg Psychiatry 1995;59: 293-8

18 DeRenzi E, Spinnler H. Visual recognition in patients with unilateral cerebral disease. $\mathcal{F}$ Nerv Ment Dis 1966;142: 515-25.

19 Gade A, Udesen H, Mortensen EL. Visual closure-the Street completion test. Nordisk Psykologi 1988;40: 194-201.

20 Brown R, Marsden C. Visuospatial function in Parkinson's disease. Brain 1986;109:987-1002.

21 Magnussen S, Sunde B, Dyrnes S. Patterns of perceptual asymmetry in processing facial expression. Cortex 1994; asymmetry in

22 Hugdahl K, Iversen PM, Ness H-M, Flaten MA. Hemispheric differences in recognition of facial expressions: A VHF-study of negative, positive and neutral emotions. Int $\mathcal{f}$ Neurosci 1989;45:205-13.

23 Stroop JR. Studies of interference in serial verbal reaction. $f$ Exp Psychol 1935;18:643-62.

24 White RF, Au R, Durso R, Moss MB. Neuropsychological function in Parkinson's disease. In: White RF, ed. Clinical syndromes in adult neuropsychology: the practi- tioner's handbook. New York: Elsevier, 1992:253-86.

25 Vilkki J. Visual hemi-inattention after ventrolateral thalamotomy. Neuropsychologia 1984;22;399-408.

26 Almgren PE, Andersson AL, Kullberg G. Differences in verbally expressed cognition following left and right ventrolateral thalamotomy. Scand 7 Psychol 1969;10.243-9.

27 Laitinen LV. Brain targets in surgery for Parkinson's disease. Results of a survey of neurosurgeons. $\mathcal{F}$ Neurosurg ease. Results of a

28 Danta G, Hilton R. Judgement of the visual vertical and horizontal in patients with parkinsonism. Neurology

29 Della-Sala S, Dilorenzo G, Giordano A, Spinnler $H$. Is there a specific visuo-spatial impairment in Parkinsonians? $\mathcal{f}$ Neurol Neurosurg Psychiatry 1986:49; 1258-65.

30 Hugdahl $\mathrm{K}$, Wester $\mathrm{K}$. Dichotic listening studies of brain asymmetry in brain damaged patients. Int $\mathcal{f}$ Neurosci 1992;63:17-29.

31 Bowen FP, Hoehn MM, Yahr MD. Parkinsonism: alterations in spatial orientation as determined by a routewalking test. Neuropsychologia 1972;10,355-61.

32 Taylor AE, Saint-Cyr JA, Lang AE. Frontal lobe dysfunction in Parkinson's disease. Brain 1986;109:845-83.

33 Lichter DG, Corbett AJ, Fitzgibbon GM, et al. Cognitive and motor dysfunction in Parkinson's disease. Clinical performance, and computed tomographic correlations. performance, and computed

34 Brown R, Marsden C. Internal versus external cues and the control of attention in Parkinson's disease. Brain 1988; 111:323-45.

35 Wester K, Hauglie-Hanssen E. The prognostic value of intra-operative observations during thalamotomy for parkinsonian tremor. Clin Neurol Neurosurg 1992;94: $25-30$ 